American Journal of Applied Sciences 6 (5): 848-856, 2009

ISSN 1546-9239

(C) 2009 Science Publications

\title{
Modeling of Oxygen Transfer Correlations for Stirred Tank Bioreactor Agitated with Atypical Helical Ribbon Impeller
}

\author{
${ }^{1}$ Mohd Shamzi Mohamed, ${ }^{1}$ Rosfarizan Mohamad, ${ }^{2}$ Ramakrishnan Nagasundara Ramanan, \\ ${ }^{3}$ Musaalbakri Abdul Manan and ${ }^{1}$ Arbakariya B. Ariff \\ ${ }^{1}$ Department of Bioprocess Technology, Faculty of Biotechnology and Biomolecular Sciences, \\ University Putra Malaysia, 43400 UPM Serdang, Selangor, Malaysia \\ ${ }^{2}$ Institute of Bioscience, Universiti Putra Malaysia, 43400 UPM Serdang, Selangor, Malaysia \\ ${ }^{3}$ Biotechnology Research Center, Malaysian Agricultural Research and Development Institute, \\ P.O. Box 12301, G.P.O. 50774, Kuala Lumpur, Malaysia
}

\begin{abstract}
Problem Statement: Mixing filamentous fungi entails delicate balance between promoting high volumetric oxygen transfer coefficient $\left(\mathrm{k}_{\mathrm{L}} \mathrm{a}\right)$ while keeping low hydrodynamic stresses in the microenvironment of cultures. This study examined the oxygen transfer capability of a prototype low shear helical impeller as a potential replacement for the standard Rushton turbine. Approach: The dependence of $\mathrm{k}_{\mathrm{L}} \mathrm{a}$ upon specific power uptake, superficial gas velocity and apparent viscosity were examined under coalescent, non-coalescent and viscous pseudoplastic fluids scenario using dynamic gassing out technique. Subsequently, collected data were treated under historical data design of response surface methodology. Results: Three empirical power law $\mathrm{k}_{\mathrm{L}}$ a correlations were developed for each fluid. Correlation comparison with literature models for single turbine agitation suggest higher $\mathrm{k}_{\mathrm{L}} \mathrm{a}$ augmentation within 1.5-3.6 folds for helical impeller in distilled water and as high as 78\% improvement in electrolytes fluid. However impeller performance is comparatively $10 \%$ lower against theoretical $\mathrm{k}_{\mathrm{L}}$ a of triple turbines arrangement for power uptake between $0-1600 \mathrm{~W} \mathrm{~m}^{-3}$. In case of carboxymethylcellulose, better oxygen transfer is expected for design with higher proportionality of impeller-to-tank internal diameter. Conclusions: Helical impeller performance as gas-liquid contactor is comparable to single and triple Rushtons turbines, with superficial gas velocity proved to be more influential than power uptake in non-viscous liquids and vice versa in viscous pseudoplastic fluids.
\end{abstract}

Key words: oxygen transfer, impeller, stirred tank bioreactor, response surface methodology

\section{INTRODUCTION}

Solubilization of oxygen in liquid medium constitutes one of the decisive factors leading to the success of fermentation processes. More often than not, wholly oxygenation of vessel would be impossible without some form of mechanical agitation ${ }^{[1]}$. Stirred tank impellers are typically classified based on the discharged flow from the blade tips, i.e., radial and axial or as indicated by the physical size with respect to tank internal diameter. Open type impellers have from one third to half of $\mathrm{D}_{\mathrm{i}} / \mathrm{D}_{\mathrm{T}}$ ratio. Else, if the diameter ratio is higher or as found in some setup, quite close to the vessel wall to effect a scraping action, impellers are otherwise generalized as proximity type agitators ${ }^{[2]}$.

Open type are primarily employed in aerobic fermentation whereas proximity types are mostly associated with the bulk blending of viscous non-
Newtonian fluids ${ }^{[3]}$. As far aerobic fermentation is concerned, $\mathrm{k}_{\mathrm{L}} \mathrm{a}$ is the yardstick for evaluating impeller performance. Extensive survey ${ }^{[4]}$ on turbines, paddles, propellers and self aeration agitators for $\mathrm{P}_{\mathrm{g}} / \mathrm{V}$ in the range of $500-10,000 \mathrm{~W} \mathrm{~m}^{-3}$ had dictated similar value of volumetric oxygen transfer coefficient $\left(\mathrm{k}_{\mathrm{L}} \mathrm{a}\right)$ correlation indices; $\mathrm{a}, \mathrm{b}$ and $\mathrm{c}$ in power law equation (1). Concluding that, under complete gas dispersion, open type impellers at equal $\mathrm{D}_{\mathrm{i}} / \mathrm{D}_{\mathrm{T}}$ can achieve the same oxygen transfer rate regardless of the different geometric designs.

$$
\mathrm{k}_{\mathrm{L}} \mathrm{a}=\mathrm{a} \cdot(\mathrm{Pg} / \mathrm{V})^{\mathrm{b}}\left(\mathrm{U}_{\mathrm{g}}\right)^{\mathrm{c}}
$$

The correlation is still relevant considering studies observed a mere $20 \%$ deviation of predicted $\mathrm{k}_{\mathrm{L}}$ a against

Corresponding Author: Arbakariya B. Ariff, Department of Bioprocess Technology, Faculty of Biotechnology and Biomolecular Sciences, Universiti Putra Malaysia, 43400 UPM Serdang, Selangor, Malaysia Telephone: +603-8946 7516 
actual data for coalescing and noncoalescing fluid systems from investigations on newer open type turbine having blades of different concavity ${ }^{[5,6]}$. Hence, no distinctive connection could be established between open type designs with regards to their effect on $k_{L} a$. Significant differences in correlation indices may come from the addition of extra turbines on the shaft ${ }^{[7-9]}$ while Vasconcelos et al. ${ }^{[10]}$ commented that retrofitting of Rushton turbine with others at equal power uptake should imply the use of larger diameter impeller to enhance the gas handling capacity.

The possibility of employing a half-pitched double blades Helical Ribbon Impeller (HRI), a novel design under close clearance category for the improvement of $\mathrm{k}_{\mathrm{L}} \mathrm{a}$ in stirred tank is the focus of this study. This being regardless of its prevalent mixing reputation in chemical industries, little are known of HRI gas-liquid oxygen transport characteristics in fermentation processes. Previous implementations were rationalized on the basis of maintaining low shear conditions for culturing fragile higher eukaryotic cells ${ }^{[11-14]}$ or capitalizing on the agitators' bulk handling and pumping capacity to homogenize highly dense and viscous broth, as reported in the quality improvement of extracellular microbial polysaccharides ${ }^{[15,16]}$.

Typical factorial experiments require changing the level of one test variable at a time whilst keeping the rest constant. Varying the impeller speed or gassing rate in non-viscous Newtonian fluid may have given satisfactory model exponent indices in Eq. 1, since the dynamic viscosity would be approximately constant at different speeds or aeration conditions. Nevertheless, it is problematic for shear-dependent fluid due to interdependency of correlator. The changes in one's parameter level will inevitable have an impact on others as well. Varied responses may require the flexibility of Response Surface Methodology (RSM) statistical tool in manipulating $\mathrm{k}_{\mathrm{L}}$ a results to arrive to the best multivariate equations. Correlations were developed for coalescent distilled water, non-coalescent electrolytes and viscous biopolymer fluids of varying concentrations. For design justification, models derived would be mutually compared to literature values of turbine impellers.

\section{MATERIALS AND METHODS}

Mixing apparatus: Experiments were performed in a 2 L stirred tank bioreactor (Biostat DCU-200, B. Braun, Germany) retrofitted with a contemporary $\mathrm{HRI}^{[17]}$. Agitator was originally developed in-house to address the complexity of mixing $M$. purpureus cultures in stirred tank bioreactor. Design can be described as a hybrid having the combinatorial feature of a halfpitched helical ribbon jointed to a bottom anchor agitator. The equipment setup is shown in Fig. 1 with the tank-impeller geometries as follows: impeller diameter $\left(D_{i}\right)=0.088 \mathrm{~m}$; pitch or vertical length for ribbon to complete a $360^{\circ}$ spiral turn $(\mathrm{s})=0.114 \mathrm{~m}$; ribbon width $(\mathrm{w})=0.008 \mathrm{~m}$; impeller height $\left(\mathrm{H}_{\mathrm{i}}\right)=0.94$ $\mathrm{D}_{\mathrm{i}}$; liquid height $\left(\mathrm{H}_{\mathrm{L}}\right)=1.5 \mathrm{D}_{\mathrm{i}}$; tank diameter $\left(\mathrm{D}_{\mathrm{T}}\right)=1.3$ $\mathrm{D}_{\mathrm{i}}$; no. of baffles $=4$; baffle width, $\mathrm{W}_{\mathrm{b}}=0.10 \mathrm{D}_{\mathrm{T}}$.

Figure 2 provides an immediate perspective on the size and looks of the design compared to Rushton turbine. A variable speed A/C motor (Heidolph, Germany) drove the impeller shaft via an in-line miniature torque transducer (TP-20KCD, Kyowa, Japan). Torque (M) was sampled at $1 \mathrm{~Hz}$ with a multichannel amplifier (PCD 300A, Kyowa, Japan) prior to recorded in a PC-based data logger.

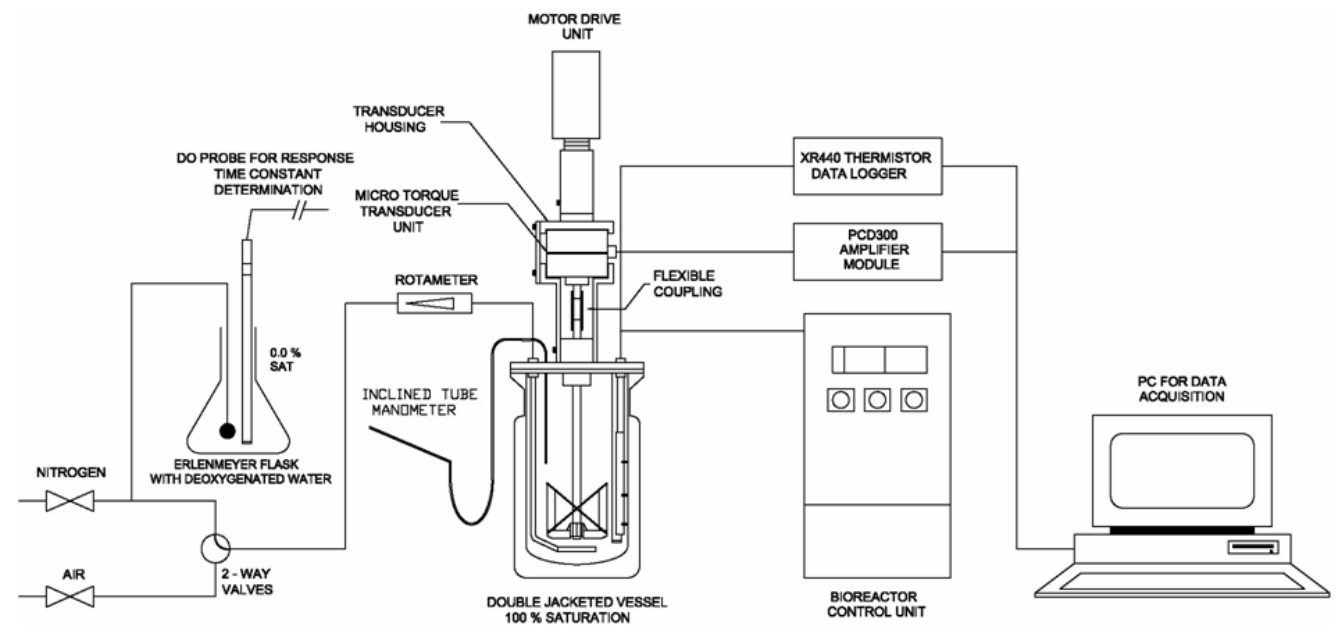

Fig. 1: Diagram of experimental setup for stirred tank bioreactor fitted with HRI agitator 

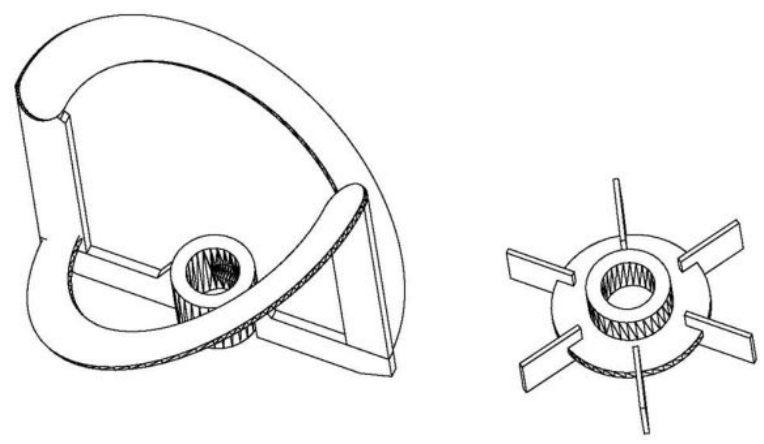

Fig. 2: Dimensional comparison between the novel double-flight helical ribbon impeller with the standard $0.333 \mathrm{D}_{\mathrm{i}} / \mathrm{D}_{\mathrm{T}}$ rushton turbine

Power draw was computed according to Eq. 2:

$\mathrm{P}=2 \pi \mathrm{N}\left(\mathrm{M}-\mathrm{M}_{0}\right)$

Volume was fixed at $1.5 \mathrm{~L}$, ensuring complete immersion of HRI blades at all time. Adjustment in stirring rate was made between 150-400 rpm (complete particles suspension to near vortexing condition) with an increment of $50 \mathrm{rpm}$ in successive run. Compressed

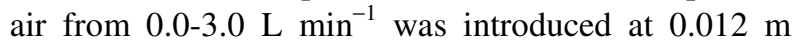
underneath the impeller via stainless steel ring type sparger.

Liquid phases: The non-viscous aqueous phases consisted of distilled water, $0.5 \mathrm{M} \mathrm{Na}_{2} \mathrm{SO}_{4}$ and synthetic fermentation medium formulated for red biopigment producing fungus $M$. purpureus FTC5391 ${ }^{[18]}$ was used in this study. This fermentation medium contained ( $\mathrm{g}$ $\mathrm{L}^{-1}$ ): glucose, 50; monosodium glutamate, $12 ; \mathrm{K}_{2} \mathrm{HPO}_{4}$, 2.5; $\mathrm{KH}_{2} \mathrm{PO}_{4}, \quad 2.5 ; \quad \mathrm{MgSO}_{4} .7 \mathrm{H}_{2} \mathrm{O}, \quad 1.0 ; \mathrm{KCl}, \quad 0.5$; $\mathrm{ZnSO}_{4} .7 \mathrm{H}_{2} \mathrm{O}, \quad 0.001 ; \quad \mathrm{FeSO}_{4} .7 \mathrm{H}_{2} \mathrm{O}, \quad 0.001$ and $\mathrm{MnSO}_{4} .7 \mathrm{H}_{2} \mathrm{O}, 0.003$. $\mathrm{pH}$ was adjusted to 6.5 either with $1.0 \mathrm{M} \mathrm{HCl}$ or $\mathrm{NaOH}$ prior to sterilization. Whereas four sets of carboxymethylcellulose sodium salt solutions, CMCNa (Prod no. 279294T, BDH, United Kingdom) with fractions of $0.2 \%, 0.4 \%, 0.6$ and $0.8 \% \mathrm{w} / \mathrm{v}$ were prepared through dilution in pre-heated distilled water to mimic the shear thinning fungal broths.

Rheology analysis: The relationship between shear stress, $\tau$ and shear rate, $\gamma$ was regressed to Ostwald de Waele power law model, as in Eq. 3 with the apparent viscosity of fluid, $\eta_{\mathrm{a}}$ estimated through Eq. 4 :

$$
\begin{aligned}
& \tau=\mathrm{K} \dot{\gamma}^{\mathrm{n}} \\
& \eta=\mathrm{K} \dot{\gamma}^{\mathrm{n}-1}
\end{aligned}
$$

Rheological profiles of $\mathrm{CMCNa}$ solutions were determined with R/S-CC controlled shear rates rheometer (Brookfield, Middleboro, United States). Measuring bob is a standard CC48 DIN cylindrical spindle with rotational speed adjustable to $1000 \mathrm{rpm}$, effectively providing test shear rate from $0-5143 \mathrm{sec}^{-1}$ and maximum shear stress of $206 \mathrm{~Pa}$. Measurement cup requires $50 \mathrm{~mL}$ of sample withdrawn from bioreactor after each $\mathrm{k}_{\mathrm{L}}$ a determination made.

Mass transfer measurement: $\mathrm{k}_{\mathrm{L}} \mathrm{a}$ was determined at $30 \pm 1.0^{\circ} \mathrm{C}$ (XR440 Thermistors, PACE Scientific, USA) through dynamic gassing out technique. DO was measured with a sterilizable polarographic electrode (InPro 6900, Mettler Toledo, Switzerland) fitted with a $25.4 \mu \mathrm{m}$ thick oxygen-selective semi permeable FEP (fluorinated ethylene propylene) membrane. To overcome erroneous $\mathrm{k}_{\mathrm{L}}$ a interpretation largely attributed to the membrane diffusional resistance, mathematical correction to the original oxygen balance model ${ }^{[19]}$ was made through the incorporation of delayed response constant, $\mathrm{k}_{\mathrm{e}}$, yielding a non-linear two "first order in series" model Eq. 5:

$\frac{\mathrm{C}_{\mathrm{p}}(\mathrm{t})}{\mathrm{C}_{\mathrm{L}}^{*}}=\left(1+\frac{\mathrm{k}_{\mathrm{L}} \mathrm{a}}{\mathrm{k}_{\mathrm{e}}-\mathrm{k}_{\mathrm{L}} \mathrm{a}} \mathrm{e}^{-\mathrm{k}_{\mathrm{e}} \mathrm{t}}-\frac{\mathrm{k}_{\mathrm{e}}}{\mathrm{k}_{\mathrm{e}}-\mathrm{k}_{\mathrm{L}} \mathrm{a}} \mathrm{e}^{-\mathrm{k}_{\mathrm{L}} \mathrm{at}}\right)$

The response time of probe, $\tau_{\mathrm{p}}=1 / \mathrm{k}_{\mathrm{e}}$, is the time for the signal output, $\mathrm{C}_{\mathrm{p}}(\mathrm{t})$, to reach $63.3 \%$ of final value following an instantaneous stepwise change from completely deoxygenated to fully saturated solution. $\tau_{p}$ was estimated at an average of $16.8 \mathrm{~s}$. The experimental DO saturation curve measured from $0 \%$ to $100 \%\left(\mathrm{C}_{\mathrm{L}}{ }^{*}\right)$ was then fitted to Eq. 5 to extract the best $\mathrm{k}_{\mathrm{L}}$ a estimate from each data set through MATLAB curve fitting module (Matlab Release 14.0, MathWorks, USA) using Gauss-Newton non-linear least square regression.

Modeling of correlations: Many articles constantly correlated $\mathrm{k}_{\mathrm{L}}$ a with the specific impeller power uptake $\left(\mathrm{P}_{\mathrm{g}} / \mathrm{V}\right)$ and superficial gas velocity $\left(\mathrm{U}_{\mathrm{g}}\right)$ expressed in an oft-cited power law form in which later reassessed for the accuracy in coefficient prediction for viscous solutions. Improvement was made through the inclusion of apparent viscosity $\left(\eta_{\mathrm{a}}\right)$ term into Eq. $1^{[20]}$. Design Expert software (version 6.0.6, Stat Ease, USA) was used to simulate the predictive $\mathrm{k}_{\mathrm{L}} \mathrm{a}$ model for the three different fluid systems. Mathematical representation of three process variables is written according to the general first order response surface model (6): 
Am. J. Applied Sci., 6 (5): 848-856, 2009

Table 1: Factor levels expressed in actual, logarithmic and coded values

\begin{tabular}{lllccccc}
\hline Factor & Symbol & Actual low & Actual high & ln low & ln high & Coded low & Coded high \\
\hline Specific power uptake, $\mathrm{P}_{\mathrm{g}} / \mathrm{V}\left(\mathrm{W} \mathrm{m}^{-3}\right)$ & $\mathrm{X}_{1}$ & 105.000 & 1860.000 & 4.655 & 7.530 & -1 & 1 \\
Superficial gas velocity, $\mathrm{U}_{\mathrm{g}}\left(\times 10^{-3} \mathrm{~m} \mathrm{sec}^{-1}\right)$ & $\mathrm{X}_{2}$ & 1.105 & 4.420 & -6.808 & -5.422 & -1 & 1 \\
Apparent viscosity, $\eta_{\mathrm{a}}$ (Pa.s) & $\mathrm{X}_{3}$ & 0.001 & 0.233 & -6.908 & -1.457 & -1 & 1 \\
\hline
\end{tabular}

$\mathrm{Y}=\beta_{0}+\sum \beta_{\mathrm{i}} \mathrm{X}_{\mathrm{i}}$

Where:

$\mathrm{Y}=$ The estimate response

$\beta_{\mathrm{i}}=$ The coefficients indicating the relative importance of the associated $\mathrm{X}$ correlator values.

Upon examining the general form of $\mathrm{k}_{\mathrm{L}} \mathrm{a}$ correlation, conformation to the linear polynomial function as in Eq. 6 was made possible by simply converting beforehand all quantitative values of test variables and the corresponding responses to natural logarithmic form leading to Eq. 7. The minimum and maximum values of variables in actual, logarithmic and coded factors are shown in Table 1.

$\ln \left(\mathrm{k}_{\mathrm{L}} \mathrm{a}\right)=\mathrm{A}+\mathrm{b} \cdot \ln \left(\mathrm{P}_{\mathrm{g}} / \mathrm{V}\right)+\mathrm{c} \cdot \ln \left(\mathrm{U}_{\mathrm{g}}\right)+\mathrm{d} \cdot \ln \left(\eta_{\mathrm{a}}\right)$

where, constant $A=\ln (a)$ taken from Eq. 1.

\section{RESULTS}

The stirred tank operating variables of $\mathrm{P}_{\mathrm{g}} / \mathrm{V}, \mathrm{U}_{\mathrm{g}}$ and $\eta_{\mathrm{a}}$ functions are dependent upon the changes made on impeller speed, gas throughput and $\mathrm{CMCNa}$ solute concentrations. For the analysis, the model of interest first took the form of linearized regression as depicted in Eq. 7. Table 2 shows the result for analysis of variance (ANOVA), for fisher-test (F-test) that is significant at $5 \%$ level (i.e., $\mathrm{p}<0.05$ ), there is evident that the model has some power to explain the variation in the response. If F-test lacks of its significant, usually a more complicated model would fit better. The F-test with a very low probability value $(\mathrm{P}>\mathrm{F}$ below than 0.05 ) has been demonstrated as to be a very high significance for the regression model. Moreover, for models' "Lack Of Fit" (LOF) which F-value higher than $5 \%$ probability level is considered not significant relative to the pure error. The LOF is the variation of the experimental data scattered around the simulated model values. If the model values did not fit well to the actual data, correlations developed will not be significant.

\begin{tabular}{|c|c|c|c|c|c|}
\hline $\begin{array}{l}\text { Source of } \\
\text { variation }\end{array}$ & $\begin{array}{l}\text { Sum of } \\
\text { square }\end{array}$ & $\begin{array}{l}\text { Degree of } \\
\text { freedom }\end{array}$ & $\begin{array}{l}\text { Mean } \\
\text { square }\end{array}$ & F-value & $\begin{array}{l}\text { Prob } \\
(\mathrm{P})>\mathrm{F}\end{array}$ \\
\hline \multicolumn{6}{|c|}{ Coalescent system $\left(R^{2}=0.9532\right)$} \\
\hline Regression & 30.15 & 2 & 15.070 & 458.74 & $<0.0001$ \\
\hline $\mathrm{X}_{1}{ }^{\circ}$ & 22.54 & 1 & 22.540 & 685.84 & $<0.0001$ \\
\hline $\mathrm{X}_{2}$ & 7.61 & 1 & 7.610 & 231.65 & $<0.0001$ \\
\hline Residual & 1.48 & 45 & 0.033 & & \\
\hline Lack of fit & 0.66 & 21 & 0.031 & 0.91 & 0.5806 \\
\hline Pure error & 0.82 & 24 & 0.034 & & \\
\hline Corr. total & 31.63 & 47 & & & \\
\hline \multicolumn{6}{|c|}{ Non-coalescent system $\left(R^{2}=0.9216\right)$} \\
\hline Regression & 39.48 & 2 & 19.740 & 264.48 & $<0.0001$ \\
\hline $\mathrm{X}_{1}$ & 37.92 & 1 & 37.920 & 508.00 & $<0.0001$ \\
\hline $\mathrm{X}_{2}$ & 1.56 & 1 & 1.560 & 20.96 & $<0.0001$ \\
\hline Residual & 3.36 & 45 & 0.075 & & \\
\hline Lack of fit & 0.98 & 21 & 0.047 & 0.47 & 0.9566 \\
\hline Pure error & 2.38 & 24 & 0.099 & & \\
\hline Corr. total & 42.84 & 47 & & & \\
\hline \multicolumn{6}{|c|}{ Viscous shear thinning fluids $\left(R^{2}=\mathbf{0 . 9 1 5 8}\right)$} \\
\hline Regression & 26.79 & 3 & 8.930 & 293.62 & $<0.0001$ \\
\hline $\mathrm{X}_{1}$ & 4.25 & 1 & 4.250 & 139.73 & $<0.0001$ \\
\hline $\mathrm{X}_{2}$ & 3.29 & 1 & 3.290 & 108.10 & $<0.0001$ \\
\hline $\mathrm{X}_{3}$ & 4.09 & 1 & 4.090 & 134.35 & $<0.0001$ \\
\hline Residual & 4.74 & 156 & 0.030 & & \\
\hline Lack of fit & 2.87 & 82 & 0.035 & 1.38 & 0.0820 \\
\hline Pure error & 1.88 & 74 & 0.025 & & \\
\hline Corr. total & 31.53 & 159 & & & \\
\hline
\end{tabular}

The goodness of fit for the multi-linear models was assessed by the determination coefficient $\left(\mathrm{R}^{2}\right)$. Each of the $\mathrm{k}_{\mathrm{L}}$ a model exhibits satisfactory $\mathrm{R}^{2}$ from $0.91-0.95$. For example, for non-coalescent distilled water, the determination coefficient $\left(\mathrm{R}^{2}=0.9532\right)$ indicates that only $4.68 \%$ of the total variations not explained by the model. The value of its adjusted determination coefficient (Adj $R^{2}$ ) is also very high, indicating a high significance of the model. The "Pred $\mathrm{R}^{2 \text { " }}$ are found to be $0.9475,0.9078$ and 0.8929 against the "Adj $\mathrm{R}^{2 \text { " of }}$ $0.9512,0.9181$ and 0.8996 for distilled water, noncoalescent electrolytes (sodium sulphate salt and $M$. purpureus medium) and the shear thinning $\mathrm{CMCNa}$ solutions, respectively.

Response surface application resulted in the generation of contour and surface plots as shown by Fig. 3. Ultimately, RSM regression would produced the following empirical polynomial relationships expressed in uncoded factor:

Case A: Coalescent distilled water system:

$\ln \left(\mathrm{k}_{\mathrm{L}} \mathrm{a}\right)=-4.1187+0.8825 \cdot \ln \left(\mathrm{P}_{\mathrm{g}} / \mathrm{V}\right)+0.765 \cdot \ln \left(\mathrm{U}_{\mathrm{g}}\right)$ 
Case B: Non-coalescent salt and M. purpureus medium system:

$\ln \left(\mathrm{k}_{\mathrm{L}} \mathrm{a}\right)=-7.7925+1.145 \cdot \ln \left(\mathrm{P}_{\mathrm{g}} / \mathrm{V}\right)+0.347 \cdot \ln \left(\mathrm{U}_{\mathrm{g}}\right)$

Case C: Shear thinning fluid system $(0.2-0.8 \% \mathrm{w} / \mathrm{v}$ $\mathrm{CMCNa}$ :

$\ln \left(\mathrm{k}_{\mathrm{L}} \mathrm{a}\right)=-4.9341+0.254 \cdot \ln \left(\mathrm{P}_{\mathrm{g}} / \mathrm{V}\right)+0.383 \cdot \ln \left(\mathrm{U}_{\mathrm{g}}\right)$

$-0.145 \cdot \ln \left(\eta_{\mathrm{a}}\right)$

Alternatively, statistical verification of model accuracy are made by calculating the mean error $(\%)$ of model values tested against a group of experimental data for each correlation as defined by Eq. 11:

Mean correlation error (\%)

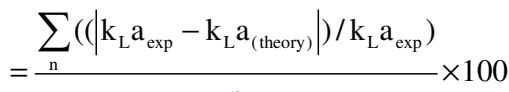

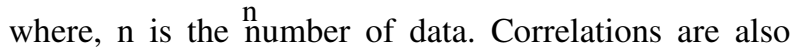
compared as well with the fitting parameter of linear regression fit (the $a_{1}$ and $a_{2}$ ) of Eq. 12. Best fitting criteria are one which provide values of ' $\mathrm{a}_{1}$ ' close to zero and ' $\mathrm{a}_{2}$ ' and the corresponding linear regression $\mathrm{R}^{2}$ close to unity:

$\mathrm{k}_{\mathrm{L}} \mathrm{a}_{\text {(theory) }}=\mathrm{a}_{1}+\mathrm{a}_{2} \cdot\left(\mathrm{k}_{\mathrm{L}} \mathrm{a}_{(\text {exp })}\right)$

The fitting parameters for the three empirical correlations reverted to power law form of equation are compiled in Table 3. From the data shown, every equation provides less than $20 \%$ of mean total error and quite satisfactory coefficient of determination $\left(\mathrm{R}^{2}\right)$ of linear fit regression. Graphical evaluation between values of $\mathrm{k}_{\mathrm{L}} \mathrm{a}$ calculated from Eq. 8-10 with the collection of experimental data are presented throughout Fig. 4-6, enclosed together with the upper and lower $20 \%$ error limits. Upon observation, around 88 to $90 \%$ of all $\mathrm{k}_{\mathrm{L}}$ a data are found to cluster within the bounded error range.

Table 4 compares the RSM models for HRI with established literatures. Correlations related to nonviscous Newtonian liquids and $0.2 \% \mathrm{w} / \mathrm{v} \mathrm{CMCNa}$ from previous reports would serve as immediate comparison with the ones developed by applying a scenario of equal specific impeller power uptake to each stirred tank system sparged at a constant 1.0 VVM.

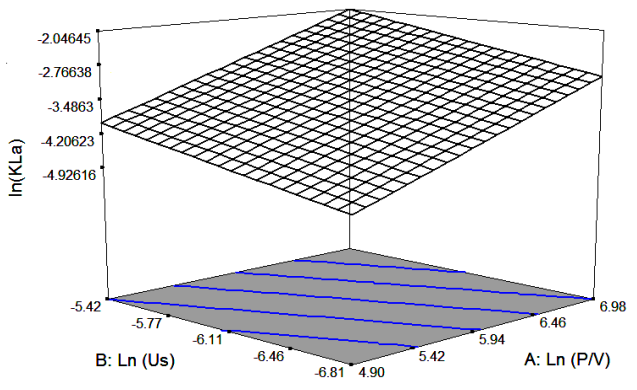

(a)

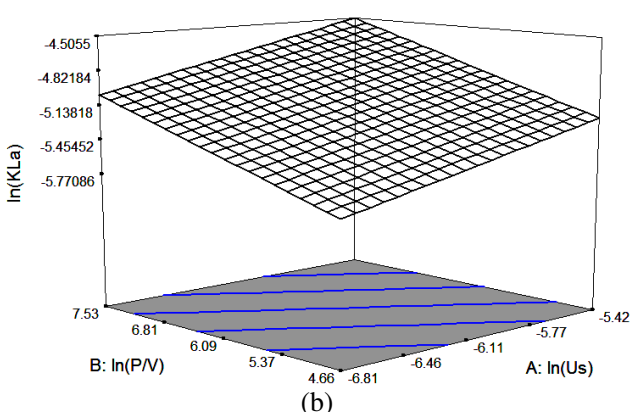

Fig. 3: Example of contour and surface plot of RSM model for (a): Distilled water system and (b): CMCNa at apparent viscosity $\eta_{\mathrm{a}}=0.0153$ Pa.s

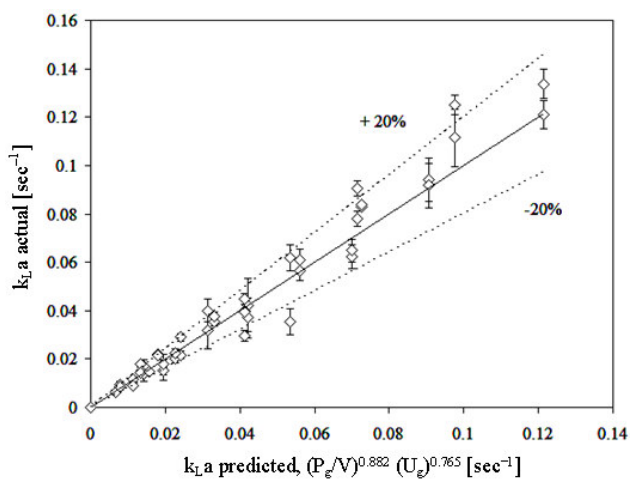

Fig. 4: Comparison of experimental $\mathrm{k}_{\mathrm{L}} \mathrm{a}$ data with theoretical values for coalescent water. (-) simulated data, (----) error limit and $(\diamond)$ distilled water

The hypothetical $\mathrm{k}_{\mathrm{L}}$ a values predicted for different set of impellers are presented in Fig. 7 and 8, respectively.

Table 3: Correlation indices, mean errors and linear regression coefficients of experimental $\mathrm{k}_{\mathrm{L}}$ a data fitted to the predictive RSM correlations

\begin{tabular}{|c|c|c|c|c|c|c|c|c|}
\hline \multirow[b]{2}{*}{ Liquid system } & \multicolumn{4}{|c|}{ Correlation indices for $\mathrm{k}_{\mathrm{L}} \mathrm{a}$ equation in power law form } & \multirow{2}{*}{$\begin{array}{l}\text { Mean } \\
\text { error } \\
(\%)\end{array}$} & \multicolumn{3}{|c|}{ Linear regression coefficients } \\
\hline & a & $\mathrm{b}$ & $\mathrm{c}$ & $\mathrm{d}$ & & $a_{1}$ & $\mathrm{a}_{2}$ & $\mathrm{R}^{2}$ \\
\hline$\overline{\text { Case A }}$ & $1.626 \times 10^{-2}$ & 0.883 & 0.765 & - & 11.34 & 0.0017 & 0.888 & 0.9785 \\
\hline Case B & $4.128 \times 10^{-4}$ & 1.145 & 0.347 & - & 18.44 & 0.0036 & 0.938 & 0.9413 \\
\hline Case C & $7.197 \times 10^{-3}$ & 0.254 & 0.383 & -0.145 & 12.59 & 0.0002 & 0.978 & 0.9292 \\
\hline
\end{tabular}


Am. J. Applied Sci., 6 (5): 848-856, 2009

Table 4: $\mathrm{k}_{\mathrm{L}} \mathrm{a}$ correlations for water, electrolyte and viscous $\mathrm{CMC}$ solutions

\begin{tabular}{|c|c|c|c|c|c|c|}
\hline \multirow[b]{2}{*}{ Stirrer type } & \multirow[b]{2}{*}{ Liquid system } & \multicolumn{4}{|c|}{ Correlation coefficients } & \multirow[b]{2}{*}{ Reference } \\
\hline & & $\mathrm{a}$ & $\mathrm{b}$ & $\mathrm{c}$ & $\mathrm{d}$ & \\
\hline Half pitched & Distilled water & $1.626 \times 10^{-2}$ & 0.883 & 0.765 & - & Present work \\
\hline \multirow[t]{2}{*}{ double- flight HRI } & $\begin{array}{l}\text { Non-coalescent: } \\
\text { i. } 0.5 \mathrm{M} \mathrm{Na}_{2} \mathrm{SO}_{4} \\
\text { ii. Fermentation media }\end{array}$ & $4.128 \times 10^{-4}$ & 1.145 & 0.347 & - & \\
\hline & Viscous CMC $(0.2-0.8 \% \mathrm{w} / \mathrm{v})$ & $7.197 \times 10^{-3}$ & 0.254 & 0.383 & -0.145 & \\
\hline Helical screw & Viscous CMC $(0.2-0.5 \% \mathrm{w} / \mathrm{v})$ & $3.420 \times 10^{-3}$ & 0.190 & 0.370 & -0.36 & Tecante et al. $^{[3]}$ \\
\hline \multirow[t]{2}{*}{ Open type } & Water & $2.600 \times 10^{-2}$ & 0.400 & 0.500 & - & Van't ${ }^{[4]}$ \\
\hline & Electrolytes solutions & $2.000 \times 10^{-3}$ & 0.700 & 0.200 & - & \\
\hline $1 \mathrm{RT}$ & $0.5 \mathrm{M} \mathrm{Na}_{2} \mathrm{SO}_{4}$ & $1.350 \times 10^{-3}$ & 0.946 & 0.400 & - & Linek et al. ${ }^{[7]}$ \\
\hline $3 \mathrm{RT}$ & $0.5 \mathrm{M} \mathrm{Na}_{2} \mathrm{SO}_{4}$ & $4.000 \times 10^{-4}$ & 1.210 & 0.400 & - & \\
\hline $1 \mathrm{RT}$ & Viscous CMC $(1.0 \% \mathrm{w} / \mathrm{v})$ & $1.070 \times 10^{-3}$ & 0.944 & 0.400 & - & \\
\hline $2 \mathrm{RT}$ & Viscous CMC $(0.25 \% \mathrm{w} / \mathrm{v})$ & $8.160 \times 10^{-4}$ & 0.680 & 0.400 & - & Arjunwadkar et al..$^{[8]}$ \\
\hline $3 \mathrm{RT}$ & Viscous CMC $(0.5 \% \mathrm{w} / \mathrm{v})$ & $2.160 \times 10^{-3}$ & 0.360 & 0.560 & - & Puthli et al. ${ }^{[9]}$ \\
\hline
\end{tabular}

$\mathrm{RT}=$ Rushton disc turbine

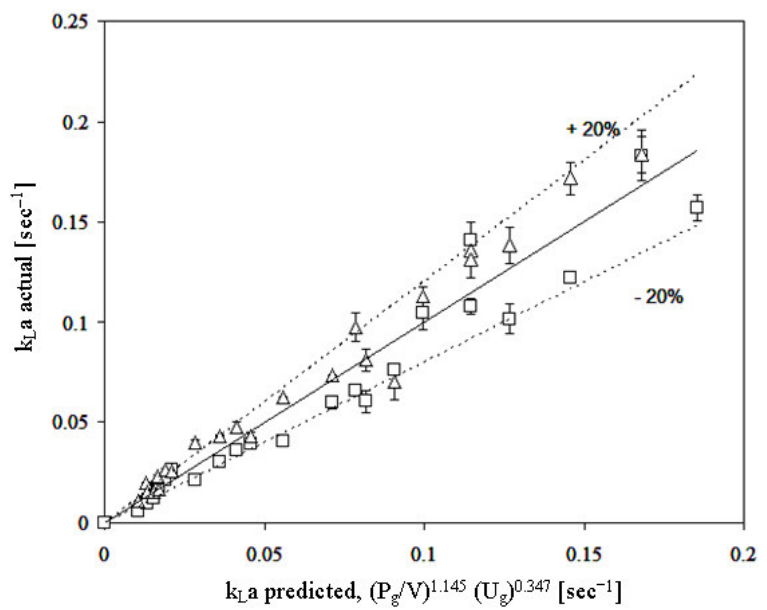

Fig. 5: Comparison of experimental $\mathrm{k}_{\mathrm{L}} \mathrm{a}$ data with theoretical values for non-coalescent electrolytes. (-) simulated data, (----) error limit, ( ) $0.5 \mathrm{M} \mathrm{Na}_{2} \mathrm{SO}_{4}$ and ( $\Delta$ ) Monascus sp. synthetic medium

\section{DISCUSSION}

Modeling exercise shows that the linear type first order surface response model chosen would adequately explained the effect of two to three affecting factors, i.e., the $\mathrm{P}_{\mathrm{g}} / \mathrm{V}, \mathrm{U}_{\mathrm{g}}$ and $\eta_{\mathrm{a}}$ on $\mathrm{k}_{\mathrm{L}}$ a only when the exact optimum point was not of particular interest.

This is rather obvious looking at the flat profile of $3 \mathrm{D}$ contour and surface plots for distilled water and concentrated CMCNa solutions featured in Fig. 3. Cumbrous higher order functions are usually required in order to detect the presence of curvature or peak in response surface and hence, closer approximation to the general vicinity of precise $\mathrm{k}_{\mathrm{L}}$ a prediction. Nevertheless, it might not be necessary for these cases since the

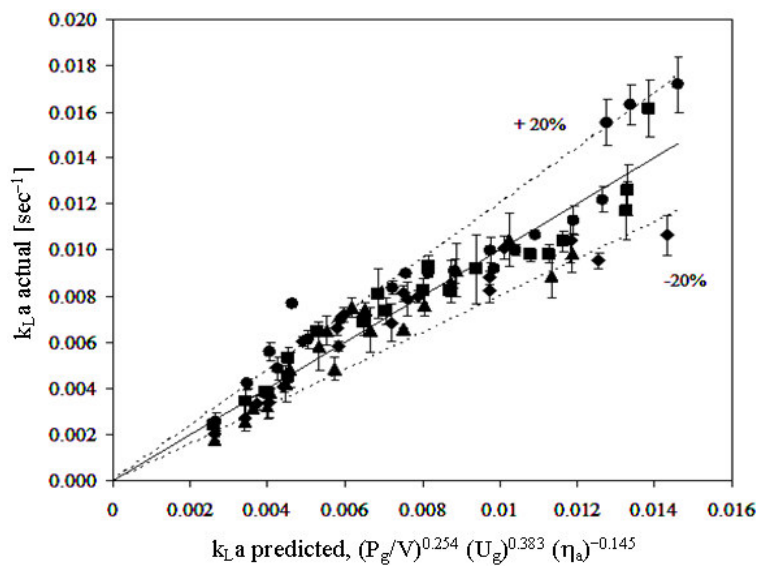

Fig. 6: Comparison of experimental $\mathrm{k}_{\mathrm{L}} \mathrm{a}$ data with theoretical values for viscous pseudoplastic samples. (-) simulated data, (----) error limit, (•) $0.2 \% \mathrm{w} / \mathrm{v},(\boldsymbol{\bullet}) 0.4 \% \mathrm{w} / \mathrm{v},(\boldsymbol{\Delta}) 0.6 \% \mathrm{w} / \mathrm{v}$ and (•) $0.8 \% \mathrm{w} / \mathrm{v} \mathrm{CMCNa}$

determination coefficient $\left(\mathrm{R}^{2}\right)$ illustrates high significance, supported by close agreement between

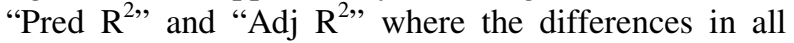
models are less than 0.2. A higher differences could have pointed out to a possible problem in the model employed or data collection $^{[21]}$.

To the best of present knowledge, no known $\mathrm{k}_{\mathrm{L}} \mathrm{a}$ correlation currently existed which is specific to halfpitched helical ribbon-anchor configurations, thus rendering it impossible to directly compare the present correlations with others obtained from identical geometry. The only available correlation in literature with particular relevance to proximity type agitator were derived for $\mathrm{CMCNa}$ solutions stirred with a helical screw impeller ${ }^{[3]}$. 
Am. J. Applied Sci., 6 (5): 848-856, 2009

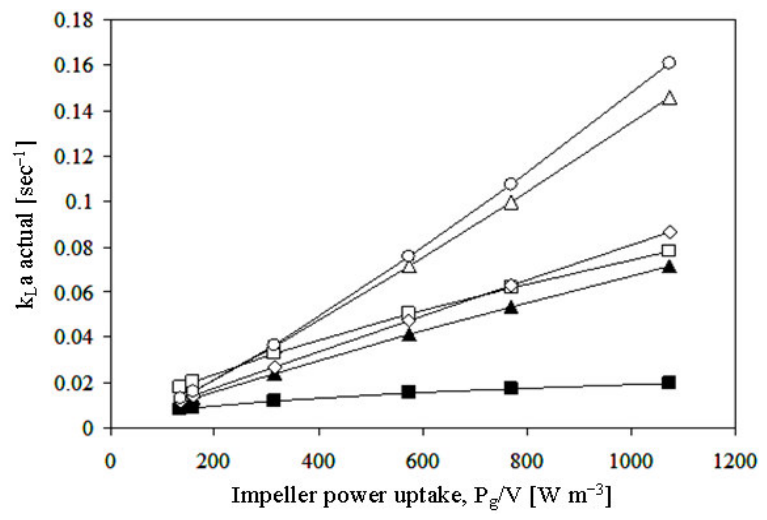

Fig. 7: Predicted $k_{L}$ a as a function of $P_{g} / V$ for water and electrolytes sparged at 1.0 VVM. (-): Van' $t^{[4]}$ model for water, $(\boldsymbol{\Delta})$ Present study for distilled water, ( ): Van' $t^{[4]}$ model for electrolyte salt, $(\diamond)$ : Linek et al. ${ }^{[7]}$ model for electrolyte salt, $(\Delta)$ : Present study for electrolyte salt and (o): Linek et al. ${ }^{[7]}$ model for three Rushton turbines in electrolytes salt

As for open type stirrers, Van't ${ }^{[4]}$ generalized correlations are well established for non-viscous fluid systems while Linek et al. ${ }^{[7]}$ correlated $\mathrm{k}_{\mathrm{L}}$ a specifically for $0.5 \mathrm{M} \mathrm{Na}_{2} \mathrm{SO}_{4}$ system. Most correlations on oxygen transfer for viscous pseudoplastic CMC lack the level variation of apparent viscosity due to anomalous rheological nature of simulant media with the agitator shearing rate ${ }^{[3,15,20]}$. As such, there is conspicuous omission of $\eta_{\mathrm{a}}$ term in the collection of $\mathrm{k}_{\mathrm{L}} \mathrm{a}$ models for Rushton turbine listed in Table 4. Most investigators would only fix the biopolymer to a single level of concentration assumed to have closest imitation of fungal viscosity ${ }^{[9]}$.

It would appear that the notion of prevailing hydrodynamics resulted from agitator geometries influencing difference $\mathrm{k}_{\mathrm{L}} \mathrm{a}$ profile is very much corroborated from these comparative analyses. Fictitious mixing with novel HRI in theory tends to perform better than a single Rushton turbine on both types of non-viscous media. Van't ${ }^{[4]}$ model has produced gross underestimation of Rushton performance against HRI agitator for water system, evident from the differences of 1.5 to 3.6 folds in $\mathrm{k}_{\mathrm{L}} \mathrm{a}$ readings between both impellers at the lowest to highest specific power uptake range. For non-coalescent electrolyte solutions, close agreement are found between Linek and Van't ${ }^{[4]}$ model for fluids mixed by a solitary Rushton turbine. Again, higher oxygen transfer performance by HRI mixing is registered for $0.5 \mathrm{M} \mathrm{Na}_{2} \mathrm{SO}_{4}$ with an average of $78 \%$ increased in $\mathrm{k}_{\mathrm{L}} \mathrm{a}$

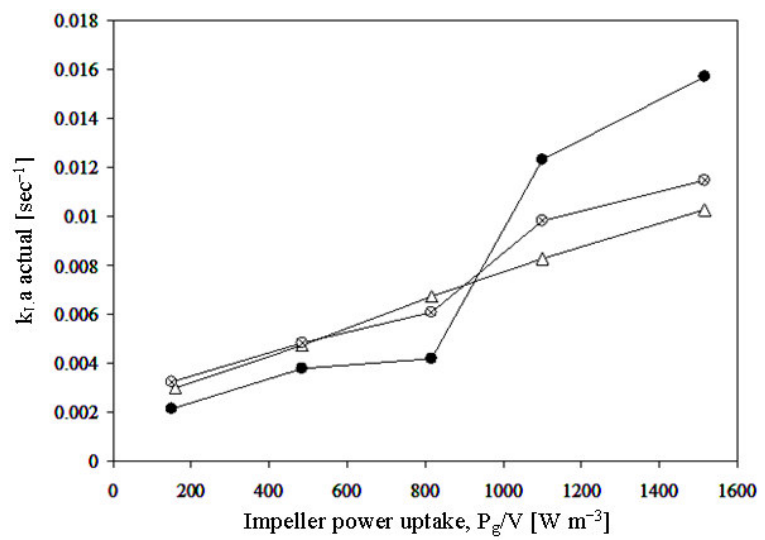

Fig. 8: Predicted $k_{L}$ a as a function of $P_{g} / V$ for $0.2 \% \mathrm{w} / \mathrm{v}$ $\mathrm{CMCNa}$ sample. $(\otimes)$ : Present study, $(\bullet)$ : Tecante et $a l \cdot{ }^{[3]}$ model for helical screw and $(\Delta)$ : Arjunwadkar et al. ${ }^{[8]}$ model for two Rushton turbines setup

when shifting to the highest impeller power uptake scale. The measure to improve the $\mathrm{k}_{\mathrm{L}} \mathrm{a}$ of open type impeller is achieved through additional numbers of Rushton turbine as indicated by Linek's model. Nonetheless in a promising outcome, three Rushton turbines affixed to a stirred tank bioreactor shaft would hypothetically provide only an average of $10 \%$ increased in $\mathrm{k}_{\mathrm{L}} \mathrm{a}$ than values from a standalone half pitched HRI system.

Judging from the flow pattern, the novel HRI design and helical screw falls under axial dispersion category. Under shear thinning fluid scenario, the particular flow pattern was predicted to fare better in mixing viscous $0.2 \% \mathrm{w} / \mathrm{v} \mathrm{CMCNa}$ than the two radial flow-type Rushton fixtures when the impeller power draw started to exceed $800 \mathrm{~W} \mathrm{~m}^{-3}$. Above this, the prototype HRI managed to produce $15-20 \%$ higher $\mathrm{k}_{\mathrm{L}} \mathrm{a}$ than Arjunwadkar et al. ${ }^{[8]}$ two turbines model. However, correlation representing the classical full pitched inner-outer helical-screw agitator having a relatively larger diameter ratio $\left(\mathrm{D}_{\mathrm{i}} / \mathrm{D}_{\mathrm{T}}=0.88\right)$ can offers up to $37 \%$ more enhancement of oxygen transfer in the upper range of $\mathrm{P}_{\mathrm{g}} / \mathrm{V}$ studied. Inferior $\mathrm{k}_{\mathrm{L}}$ a values below $800 \mathrm{~W} \mathrm{~m}^{-3}$ for helical screw compared to others may be attributed to the absence of horizontal turbine disc or baffles structure. The spinning disk helps to create lower pressure region in bioreactor to redirect the bubbles passage into the high shearing region of the blades while baffles can create additional breakup near the tank wall areas ${ }^{[2]}$. Nevertheless as the power input increases, the energy dissipated by the close clearance geometry could have created higher turbulence throughout the stirred tank environment and increases the liquid drag force. Thereby reducing the bubbles 
upward rise velocity and in turn, achieved more contact with the revolving screw.

Tecante et al. ${ }^{[3]}$ had perceived that the effectiveness of axial flow close clearance impeller to be strongly dependent on gassing rate rather than the specific power uptake (agitation intensity) in viscous pseudoplastic system, which is an obvious inverse from the established correlations for radial flow Rushton turbine. By obtaining a slightly similar exponent index for $\mathrm{P}_{\mathrm{g}} / \mathrm{V}$ variable with the aforementioned work and noting that the exponent for $\mathrm{U}_{\mathrm{g}}$ in this study to be 1.5 times more influential than value recorded for $\mathrm{P}_{\mathrm{g}} / \mathrm{V}$ (Eq. 10) as opposed to correlations for non-viscous cases, the findings further lends credibility to the previous investigators' point of view. In the two turbines system, the scenario may have suggested that mixing mechanism of turbulent eddies primarily induced by the fluid entrained by its remote stirring within the $\mathrm{P}_{\mathrm{g}} / \mathrm{V}$ range applied might still be insufficient to penetrate the viscous boundary layers affecting bubbles break-up and consequently, led to the low global oxygen transfer in mixing vessel, thus resulting in poorer overall $\mathrm{k}_{\mathrm{L}} \mathrm{a}$ performance for Rushton turbine compared to the two cases utilising helical type close clearance impellers.

\section{CONCLUSION}

The RSM treatment on historical $\mathrm{k}_{\mathrm{L}} \mathrm{a}$ dataset for correlation development was considered successful in providing good statistical fit between calculated and experimental data within $\pm 20 \%$ error level. The correlations adequately describe the effect of operating variables and fluid properties with $\mathrm{k}_{\mathrm{L}} \mathrm{a}$ augmentation to be primarily dependent more on impeller power uptake for non-viscous media. Nevertheless rheological modification towards viscous shear thinning conditions collectively caused the effect of superficial gas velocity, $\mathrm{U}_{\mathrm{g}}$ to be more influential than $\mathrm{P}_{\mathrm{g}} / \mathrm{V}$ term. Upon comparison with literature models, HRI hypothetically fares better as gas-liquid contactor than a single Rushton turbine and also quite remarkable when compared against a triple arrangement. In pseudoplastic solutions, design having larger wall to blades clearance would perform better above a certain power uptake. On that basis, the $\mathrm{k}_{\mathrm{L}}$ a correlation obtained from the current system actually can be assumed to give more valid representative of a well mixed gas-liquid phase and uniform bulk mixing in stirred tank than what was reported for the turbulent open type stirrer system.

\section{REFERENCES}

1. Finn, R.K., 1954. Agitation-aeration in the laboratory and industry. Bacteriol. Rev., 18: 254274. http://mmbr.asm.org/cgi/reprint/18/4/254.
2. Hemrajani, R.R. and G.B. Tatterson, 2004. Mechanically Stirred Vessels. In: Handbook of Industrial Mixing Paul, E.L., V.A. Atiemo-Obeng and S.M. Kresta (Eds.). John Wiley and Sons, New Jersey, USA, ISBN: 0471269190, pp: 345-390.

3. Tecante, A., E. Brito de la Fuente, L. Choplin and P.A. Tanguy, 1996. Oxygen Transfer in NonNewtonian Fluids Stirred with a Helical Ribbon Screw Impeller. In: Advances in Engineering Fluid Mechanics: Multiphase Reactor and Polymerization System Hydrodynamics, Cheremisinoff, N.P. (Ed.). Gulf Professional Publishing, Houston, USA. ISBN: 0872014924, pp: 431-453.

4. Van't Riet, K. and J. Tramper, 1991. Basic Bioreactor Design. Marcel Dekker Inc., New York, USA., ISBN: 0824784464, pp: 236-273.

5. Chen, Z.D. and J.J.J. Chen, 1999. Comparison of mass transfer performance for various single and twin impellers. Chem. Eng. Res. Des., 77: 104-109. http://www.cheric.org/research/tech/periodicals/vol _view.php?seq=52077.

6. Zhu, Y., P.C. Bandyopadhyay and J. Wu, 2001. Measurement of gas-liquid mass transfer in an agitated vessel- A comparison between different impellers. J. Chem. Eng. Jap., 34: 579-584. http:// sciencelinks.jp/j-east/article/200116/000020011601 A0545489.php.

7. Linek, V., V. Vacek and P. Benes, 1987. A critical review and experimental verification of the correct use of the dynamic method for the determination of oxygen transfer in aerated agitated vessels to water, electrolyte solutions and viscous liquids. Chem. Eng. J., 34: 11-34. http://cat.inist.fr/? aModele $=$ afficheN\&cpsidt $=8009373$.

8. Arjunwadkar, S.J., K. Sarvanan, P.R. Kulkarni and A.B. Pandit, 1998. Gas-liquid mass transfer in dual impeller bioreactor. Biochem. Eng. J., 1: 99-106. DOI: 10.1016/S1385-8947(97)00083-1.

9. Puthli, M.S., V.K. Rathod and A.B. Pandit, 2005. Gas-liquid mass transfer studies with triple impeller system on a laboratory scale bioreactor. Biochem. Eng. J., 23: 25-30. DOI: 10.1016/j.bej.2004.10.006.

10. Vasconcelos, J.M.T., S.C.P. Orvalho, A.M.A.F. Rodrigues and S.S. Alves, 2000. Effect of blade shape on the performance of six-bladed disk turbine impellers. Ind. Eng. Chem. Res., 39: 203-213. http://pubs.acs.org/cgi-bin/article.cgi/ iecred/2000/39/i01/pdf/ie9904145.pdf.

11. Kamen, A.A., R.L. Tom, A.W. Caron, C. Chavarie, B. Massie and J. Archambault, 1991. Culture of insect cells in helical ribbon impeller bioreactor. Biotechnol. Bioeng., 38: 619-628. DOI: 10.1002/bit.260380607. 
12. Archambault, J., R.D. Williams, L. Lavoie, M.F. Pepin and C. Chavarie, 1994. Production of somatic embryos in a helical ribbon impeller bioreactor. Biotechnol. Bioeng., 44: 930-943. DOI: 10.1002/bit.260440809.

13. Tom, R.L., M.T. Debanne, C. Badard, A.W. Caron, B. Massie and A.A. Kamen, 1995. Improved yields of the extracellular domain of the epidermal growth factor receptor produced using the baculovirus expression system by medium replacement following infection. Applied Microbiol. Biotechnol., 44: 53-58. DOI: 10.1007/s002530050519.

14. Meyer, J.E., M. Pépin and M.A.L. Smith, 2002. Anthocyanin production from Vaccinium pahalae: Limitations of the physical microenvironment. J. Biotechnol., 93: 45-57. DOI: 10.1016/S01681656(01)00378-9.

15. Vuyst, L.d., A. Vermeire, J.V. Loo and E.J. Vandamme, 1987. Nutritional, physiological and process-technological improvements of the xanthan fermentation process. Proceedings of the 1st Forum for Applied Biotechnology, Oct.1-1, Rijksuniversiteit Gent, Denmark, Belgium, pp: 1881-1900. http://www.fao.org/agris/search/ display.do?f=./1990/v1602/BE8901354.xml;BE89 01354.
16. Dreveton, E., F. Monot, D. Ballerini, J. Lecourtier and L. Choplin, 1994. Effect of mixing and mass transfer conditions on gellan production by Auromonas elodea. J. Ferment. Bioeng. 77: 642-649. http://ci.nii.ac.jp/naid/ $110002681853 /$.

17. Delaplace, G., J.C. Leuliet and V. Relandeau, 2000. Circulation and mixing times for helical ribbon impellers. Rev. Exp. Exp. Fluids, 28: $\quad$ 170-182. http://cat.inist.fr/? aModele $=$ afficheN\&cpsidt $=1258867$.

18. Lin, T.F and A.L. Demain, 1991. Effect of nutrition of Monascus sp. on formation of red pigments. App. Microbiol. Biotechnol., 36: 7075.DOI: 10.1007/BF00164701.

19. Bandyopadhyay, B., A.E. Humphrey and H. Taguchi, 1967. Dynamic measurement of the volumetric oxygen transfer coefficient in fermentation systems. Biotechnol. Bioeng., 9: 533-544. DOI: 10.1002/bit.260090408.

20. Olsvik, E. and B. Kristiansen, 1994. Rheology of filamentous fermentations. Biotechnol. Adv., 12: 1-39. http://www.ncbi.nlm.nih.gov/pubmed/ 14547817.

21. Montgomery, D.C., 2001. Design and Analysis of Experiments. 6th Edn., John Wiley and Sons Inc., New York. ISBN: 0471661597, pp: 373-401. 